\title{
SENSITIVITY OF RESOLVED MOUNTAIN DRAG TO MODEL RESOLUTION FOR MAP CASE STUDIES.
}

\author{
Samantha A. Smith ${ }^{1}$, James D. Doyle ${ }^{2}$, Andrew Brown ${ }^{1}$ and Stuart Webster ${ }^{1}$ \\ ${ }^{1}$ Met Office, Fitzroy Road, Exeter, EX1 3PB, UK \\ ${ }^{2}$ Naval Research Laboratory, Monterey, CA 93943-5502 \\ E-mail: samantha.smith@metoffice.gov.uk
}

\begin{abstract}
Seven mountain wave case studies from the Mesoscale Alpine Programme (MAP) have been used to investigate the variation in the resolved surface pressure drag due to the Alps with model horizontal resolution. The three independent modelling systems tell the same story. For cases with small southerly (or northerly) wind-speeds near mountain crest level $\left(<10 \mathrm{~m} \mathrm{~s}^{-1}\right)$, most of the drag was produced by low-level flow splitting around the Alpine barrier and the drags were converging. For situations where the southerly (or northerly) wind component increased strongly with height due to the location of the jet-stream directly above the Alps, the larger wind-speeds near mountain crest level forced much stronger mountain waves in the flow aloft. For such cases, the drag increased strongly as the grid-spacing was reduced from $12 \mathrm{~km}$ to $4 \mathrm{~km}$. This has important consequences for the use of drag parameterisations.
\end{abstract}

Keywords - drag, mountain waves

\section{INTRODUCTION}

Very little is known about the resolution dependence of resolved mountain drag forecast by NWP models, particularly for mountain ranges as complex and 3-dimensional at a wide range of scales such as the Alps. Clark and Miller (1991) found that for a single case of strong south foehn which occurred on 8 November 1982 , convergence was achieved at a horizontal resolution of $10 \mathrm{~km}$. This may, however, have been due to the $10 \mathrm{~km}$ resolution of their source orography dataset. The present paper aims to extend this study by producing more realistic simulations of seven significant drag cases identified during the Mesoscale Alpine Programme or MAP. The global simulations were initialised by analyses and the mesoscale simulations were driven by boundary conditions produced by these global forecasts, so that the horizontal variability of the atmosphere and temporal variations in the upstream conditions are represented. In addition, model orography was obtained from much higher resolution $(1 \mathrm{~km})$ datasets. The robustness of the results are increased by producing simulations using three independent modelling systems. These models are the Met Office Unified Model (UM), the Naval Research Laboratory (NRL) Coupled Ocean/Atmosphere Mesoscale Prediction System (COAMPS ${ }^{T M}$ ) and the European Centre for Medium range Weather Forecasting (ECMWF) Integrated Forecast System (IFS). Table 1 summarises the situation on each day (see the MAP website for more details). The mountain waves observed during the various aircraft sorties were generally of small to moderate amplitude with horizontal wavelengths between $6 \mathrm{~km}$ and $30 \mathrm{~km}$.

\section{RESOLVED SURFACE PRESSURE DRAGS}

It can be deduced from Table 1 that the surface drag is strongest when the large scale wind at low levels has a large southerly (or northerly) component. The preferred NW-SE (or vice-versa) orientation of the drag vector seems qualitatively reasonable given the shape of the Alpine barrier. As the horizontal grid resolution is increased from $120 \mathrm{~km}$ to $4 \mathrm{~km}$, more of the orographic detail is captured as shown in Fig. 1. Fig. 2 shows that the resolved surface drag magnitude increases monotonically with horizontal resolution. The lowest resolution grid of $125 \mathrm{~km}$ (Fig. 1a) is far too course to capture even the general shape of the Alpine barrier. Hence the relative large drag increases from $120 \mathrm{~km}$ to $60 \mathrm{~km}$ is due to the models beginning to capturing the flow around the Alps as a whole. At higher resolutions, the rate of increase of the drag magnitude will be determined by the relative importance of the various scales in the momentum budget. For the 2 and 13 November 
Table 1: Situation for each of the seven case studies. The first two columns after the date give the large-scale wind direction and the magnitude of the southerly (or northerly) wind component $\mathrm{V}$ at a height of $4 \mathrm{~km}$ above mean sea level (msl). Also given is the relative amplitude of the mountain waves (MW) and the surface drag magnitude and direction predicted by the $4 \mathrm{~km}$ resolution models. Differentiating features of each case are also indicated.

\begin{tabular}{lccccc}
\hline \hline Date & Wind Direc & V at $4 \mathrm{~km}$ & MW Amp & Drag Mag & Drag Dir \\
\hline \hline 20 Sep & S & 19 & Large & Large & SS \\
\hline 21 Oct & S & 17 & Large & Large & ESE \\
\hline 25 Oct & SW & 17 & Large & Large & SSE \\
\hline 2 Nov & SW & 5 & Small & Small & SSE \\
\hline 6 Nov & W/S & 5 & Moderate & Small & S \\
\hline 8 Nov & NNW & 16 & Large & Large & NNW \\
\hline 13 Nov & - & 5 & Small & Small & ESE \\
\hline \hline
\end{tabular}
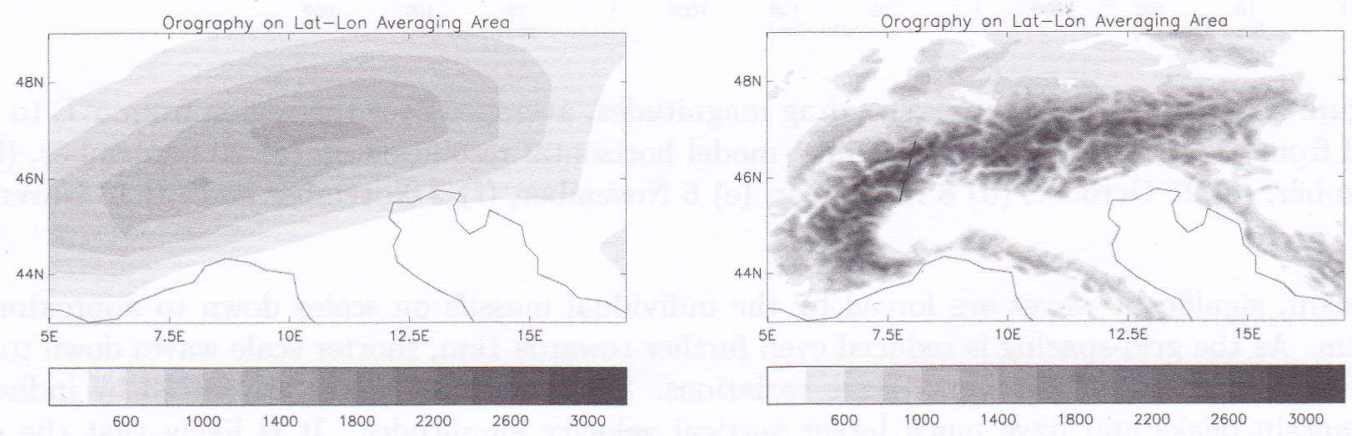

Figure 1: The Alps as represented on the UM model grid at horizontal resolutions of (a) $120 \mathrm{~km}$ and (b) $4 \mathrm{~km}$. Only the drag averaging area $\left(5^{\circ}\right.$ to $17^{\circ} \mathrm{E}, 43^{\circ}$ to $\left.49^{\circ} \mathrm{N}\right)$ is shown. The position of the transect for which data is plotted in Fig. 3 is shown in (b).

cases, the drag is starting to converge by a resolution of $4 \mathrm{~km}$ in UM and COAMPS. Most of the drag is produced by low-level flow splitting around the Alps, which should be captured at relatively low resolutions. (Convergence was confirmed by $2 \mathrm{~km}$ and $1 \mathrm{~km}$ UM simulations for the 2 November case).

For the other cases, the drag continues to increase strongly at all resolutions shown (down to $1 \mathrm{~km}$ resolution for the 8 November case, not shown). The relative wave amplitudes produced by the $4 \mathrm{~km}$ simulations are given in Table 1 , which shows that the drag magnitudes are larger for cases where the wave amplitudes are larger. These are cases where the jet stream lies directly over the Alps, producing an increasing southerly (or northerly) wind magnitude with height to a value $>15 \mathrm{~m} \mathrm{~s}^{-1}$ near mountain crest level. This suggests that a significant proportion of the total drag is produced by gravity waves in the flow aloft at scales which are not yet well-resolved in the simulations. To demonstrate how the wave amplitudes increase with horizontal model resolution, data has been extracted from the 8 November simulations along the track shown in Fig. 1(b). Fig. 3(b) shows that closer grid-spacing captures surface height variability on a wider variety of scales, with the addition of the smaller scales increasing the height of the mountain peaks and the depth of the valleys between them. Fig. 3(a) shows the vertical velocities at 1200 UTC at a height of $5670 \mathrm{~m}$ along this track at each model resolution. The vertical velocities exhibit very little wave activity for grid-spacings of $12 \mathrm{~km}$ or longer. At these resolutions, wavelengths shorter than $72 \mathrm{~km}$ (6 grid-lengths) will not be, or only very poorly, resolved. As the grid-spacing is reduced 

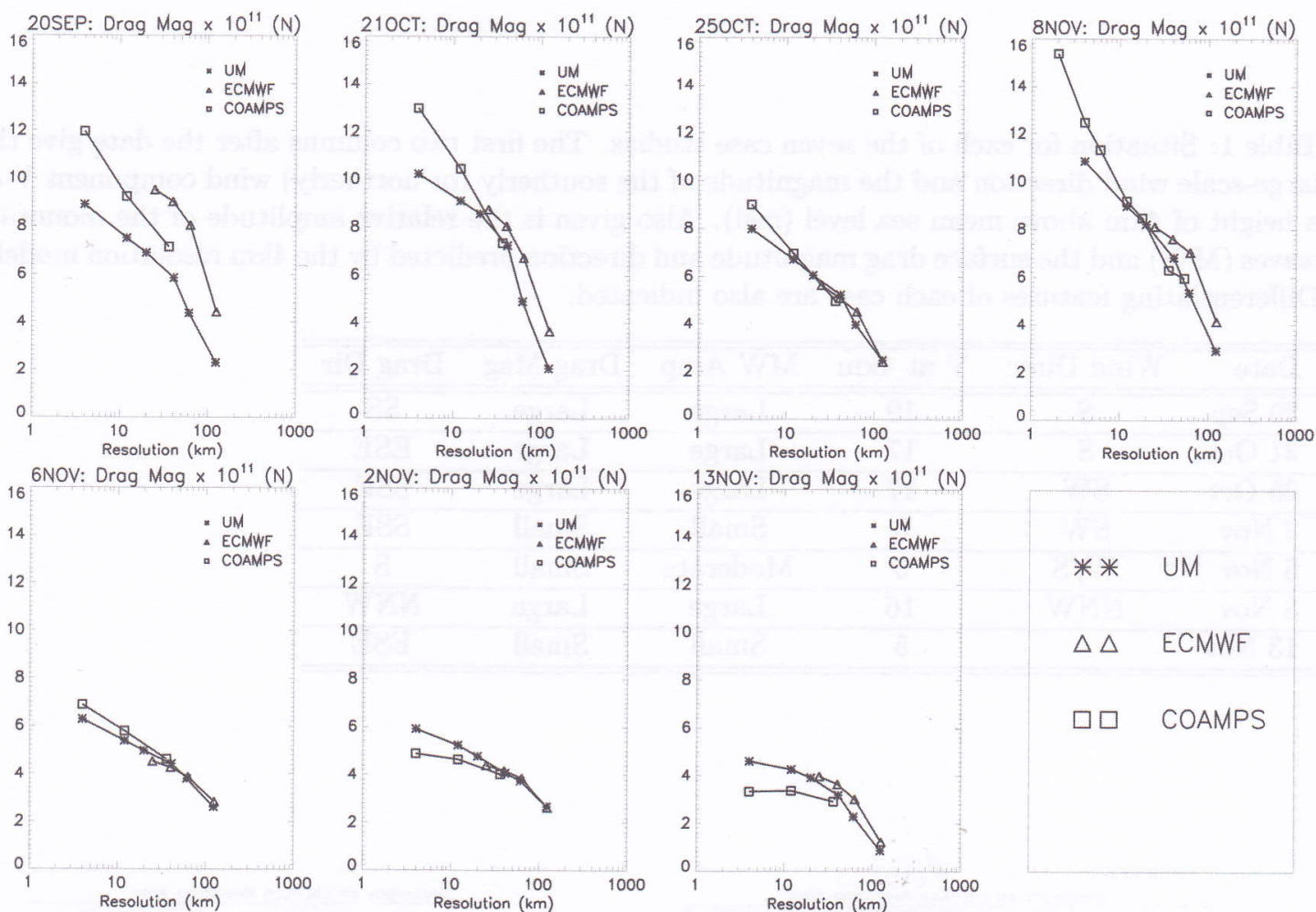

Figure 2: Resolved surface pressure drag magnitudes, averaged over the region from $5^{\circ} \mathrm{E}$ to $17^{\circ} \mathrm{E}$ and from $43^{\circ} \mathrm{N}$ to $49^{\circ} \mathrm{N}$, plotted against model horizontal resolution on (a) 20 September, (b) 21 October, (c) 25 October, (d) 8 November, (e) 6 November, (f) 2 November and (g) 13 November.

to $4 \mathrm{~km}$, significant waves are forced by the individual massifs on scales down to approximately $24 \mathrm{~km}$. As the grid-spacing is reduced even further towards $1 \mathrm{~km}$, shorter scale waves down to $6 \mathrm{~km}$ are superimposed on the longer scale variations. These shortest waves are forced by individual mountain peaks and have much larger vertical velocity amplitudes. It is likely that the small scale wave amplitudes would increase if the grid-spacing was further reduced so that they are fully resolved.

\section{CONCLUSION}

In this paper, seven mountain wave case studies from the Mesoscale Alpine Programme (MAP) have been used to investigate the variation in the resolved surface pressure drag due to the Alps with model horizontal resolution. All three independent modelling systems tell the same story with regards to the variation of the resolved drag with horizontal resolution. For cases with small southerly (or northerly) wind-speeds near mountain crest level $\left(<10 \mathrm{~m} \mathrm{~s}^{-1}\right)$, most of the drag was produced by low-level flow splitting around the Alpine barrier and the drags were converging. For situations where the southerly (or northerly) wind component increased strongly with height due to the location of the jet-stream directly above the Alps, the larger wind-speeds near mountain crest level forced much stronger mountain waves in the flow aloft. For such cases, the drag increased strongly as the grid-spacing was reduced from $12 \mathrm{~km}$ to $4 \mathrm{~km}$. For the 8 November case, the drag continued to increase as the grid-spacing was reduced further to $1 \mathrm{~km}$, suggesting that waves at scales as small as $6 \mathrm{~km}$ might play a significant role in the momentum budget.

\section{ACKNOWLEDGEMENTS}

COAMPS is a trademark of the Naval Research Laboratory. Research support for the second 

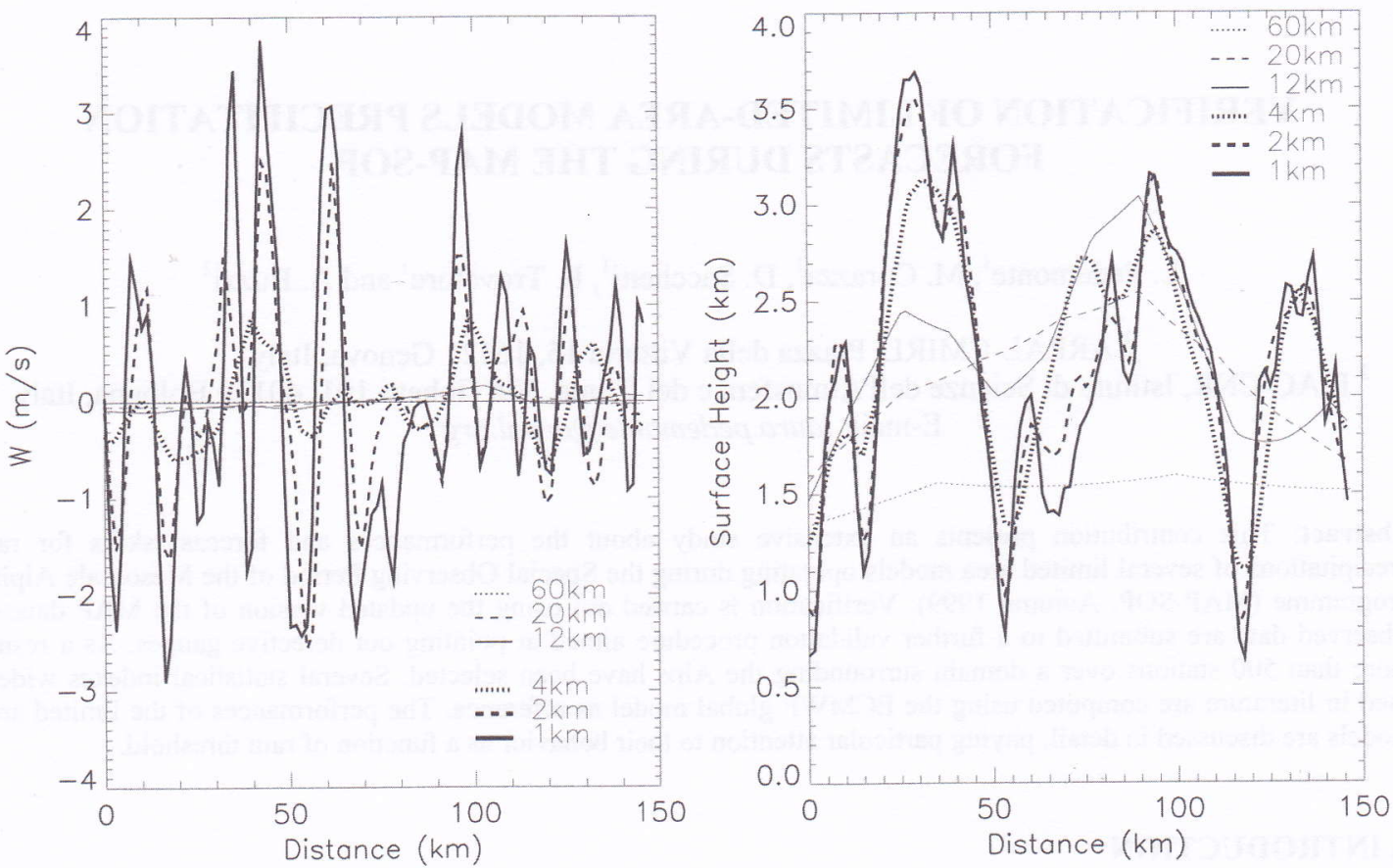

Figure 3: (a) 8 November 12:00 vertical velocity time-series at a height of 5670m from the UM and (b) Underlying model orography along the transect shown in Fig. 1b

author (JDD) was provided by ONR PE0601153N.

\section{REFERENCES}

Clark, T. L., and Miller, M. J., 1991. Pressure drag and momentum fluxed due to the Alps II: Representation in large-scale atmospheric models. Quarterly Journal of the Royal Meteorological Society, 117: 527-552. 